\title{
Influence of exploration time on haptic and visual matching of complex shape*
}

\author{
PHILIP W. DAVIDSON $\dagger$, SALLY ABBOTT, and JEAN GERSHENFELD \\ Washington College, Chestertown, Maryland 21620
}

\begin{abstract}
The time adult Ss were allowed to explore stimuli was varied during intra- and cross-model equivalence matching involving vision and touch. Increasing time to explore either each standard, each comparison, or both standard and comparison from 4 to 16 sec significantly improved haptic intramodel matching. However, cross-modal matching, from either vision to touch or touch to vision, improved significantly only when time to explore each standard was increased. Videotape recordings of Ss' hand movements revealed use of a greater variety of haptic scanning strategies by Ss in groups where increased exploration time enhanced accuracy. The difference in effects of exploration time on intra- compared to cross-model shape matching was discussed in terms of possible differences in requirements between the two tasks.
\end{abstract}

Studies of shape matching between and within vision and touch have consistently shown that the eye is more accurate than the hand. This outcome has been reported in studies of adults (cf. Abravanel, 1973; Goodnow, 1971 ) as well as children (cf. Goodnow, 1971; Milner \& Bryant, 1968; Rose, Blank, \& Bridger, 1972; Rudel \& Teuber, 1964), and seems to occur as long as at least one part of the task, i.e., exploring standards or exploring comparisons, is accomplished by touch.

One factor that may account for the less accurate judgments by hand is the successive nature of haptic information pickup. Revesz pointed out (1950) that the amount of information the hand can gather simultaneously is limited by the requirement of proximal contact. Prehending the "whole" form involves taking a number of tactile samples over time (Revesz, 1950 , p. 61). The eye, unlimited in this manner, is capable of prehending a much greater amount of information per unit time than touch. While the effects of the characteristic of successiveness are unclear, several investigators have argued that its limitation in prehending whole aspects of the stimulus leads to inefficient coding of tactual input and/or less stable haptic memory (Davidson, Barnes, \& Mullen, in press; Davidson \& Whitson, 1974; Goodnow, 1971; Milner \& Bryant, 1968; Rose, Blank, \& Bridger, 1972).

One question raised by the above hypothesis involves the time afforded Ss to explore stimuli by eye and by hand in matching experiments. If the hand gathers less

*This research was supported by USPHS Research Grant 1-R01-EY-00807-01 from the National Eye Institute to the first author. Preparation of the manuscript was supported in part by Maternal and Child Health Services Project No. 916 to the Division for Disorders of Development and Learning, University of North Carolina, and in part by USPHS Grant HD-03110 to the Biological Science Research Center, University of North Carolina. We wish to thank J. Goodnow for making her free-form solids set available to us to copy, and ultimately, Professor James Gibson, from whom she obtained them. We are indebted also to $\mathrm{M}$. Belcher for scoring the videotaped data.

tRequests for reprints should be sent to Philip W. Davidson. Division for Disorders of Development and Learning, Child Development Institute, University of North Carolina, Chapel Hill, N.C. 27514. information per unit time than the eye, and exploration time is limited as it usually is in such experiments to a few seconds (cf. Abravanel, 1973; Goodnow, 1971; Jackson, 1973; Milner \& Bryant, 1968; Rudel \& Teuber, 1964), touch may be influenced to a greater degree than vision. Indeed, the few studies that either increased haptic exploration time (Raskin \& Scoonover, 1972) or permitted unlimited time for haptic search (Rose, et al, 1972; Johnson, 1972) found that haptic judgments improved, and, in the case of the latter two experiments, were similar to visual judgments.

The present study examined how exploration time affects accuracy in matching by eye and by hand, and also, how Ss make use of the exploration time. Our starting point was Goodnow's (1971) comparison of haptic and visual matching using Gibson's (1962) free-form solids. (These stimuli are noted for being unfamiliar to both touch and vision, and difficult to discriminate by either naming, or counting features, cf. Caviness, 1964.) In one part of Goodnow's (1971) experiment, the Ss matched standards from comparison arrays of three stimuli, each presented for $4 \mathrm{sec}$ in succession. The results showed that visual intramodal matching was nearly errorless, while accuracy in haptic intra- and intermodal matching was between $60 \%$ and $75 \%$.

In Experiment I, we replicated Goodnow's intramodal matching conditions, while adding haptic groups allowed additional time to explore standards only, comparisons only, or both. We also recorded the haptic exploratory activity of each $S$ in each group on videotape to see how scanning was influenced by exploration time. In Experiment II, we followed similar procedures to study cross-modal matching.

\section{EXPERIMENT I}

\section{Method}

Subjects. Forty undergraduate volunteers participated in the study. 
Table 1

Mean Intramodal Matching Errors

\begin{tabular}{|c|c|c|c|c|c|c|}
\hline \multirow{3}{*}{$\begin{array}{c}\text { Time } \\
\text { to Feel } \\
\text { Compar- } \\
\text { isons } \\
\text { (Sec) }\end{array}$} & \multicolumn{2}{|c|}{ Time to Feel } & \multicolumn{2}{|c|}{ Standards } & \multirow{2}{*}{\multicolumn{2}{|c|}{$\begin{array}{c}\text { Visual } \\
\text { Control }\end{array}$}} \\
\hline & \multicolumn{2}{|c|}{$4 \mathrm{Sec}$} & \multicolumn{2}{|c|}{$16 \mathrm{Sec}$} & & \\
\hline & Mean & SD & Mean & SD & Mean & SD \\
\hline $\begin{array}{r}4 \\
16\end{array}$ & $\begin{array}{l}6.62 \\
3.62\end{array}$ & $\begin{array}{l}2.91 \\
2.54\end{array}$ & $\begin{array}{l}3.37 \\
2.50\end{array}$ & $\begin{array}{l}2.05 \\
2.34\end{array}$ & 0.25 & 0.71 \\
\hline
\end{tabular}

Stimuli. The stimuli were the series of free-form solids described by Gibson (1962). The series consisted of 10 smooth sculpted three-dimensional forms, each approximately $10 \mathrm{~cm}$ across and $6 \mathrm{~cm}$ high and weighing around $150 \mathrm{~g}$. Each stimulus consisted of a humped top surrounded by five protuberances, and a smooth concave bottom. The relationships between the hump and five protuberances and among the protuberances themselves differed for each stimulus, as did the shapes of the protuberances and hump and the spaces separating them.

Procedure. Each $S$ explored first a standard stimulus, then three successively presented comparison stimuli to match the standard. Each of the 10 solids served as a standard twice in random order for a total of 20 trials. Inclusion and ordering of comparison stimuli was random, and the correct stimulus was always present in the comparison array.

Sixteen Ss were assigned randomly to each of the two haptic intramodal matching groups and eight $S$ s to a visual intramodal control group. The first haptic group explored standards for $4 \mathrm{sec}$, with half of the Ss given $4 \mathrm{sec}$ to explore each comparison $(\mathrm{TT}-4,4)$ and the other half, $16 \mathrm{sec}(\mathrm{TT}-4,16)$. The second haptic group explored standards for $16 \mathrm{sec}$, with half of the Ss allowed $4 \mathrm{sec}$ for each comparison (TT-16,4) and the other half, $16 \mathrm{sec}$ for each comparison (TT-16,16). The visual group explored standards and comparisons for 4 sec each $(V V-4,4)$.

For haptic matching, blindfolded Ss held the stimulus in the nonpreferred hand, convex bottom in palm, and explored the upper portion with the other hand. For visual matching, Ss sat before a small, curtain-covered stage made from a cardboard box. Each stimulus was placed on the stage with the curtain closed and viewing time controlled by raising and lowering the curtain with a string. In all conditions, each stimulus was always presented in the same orientation (haptic groups were instructed not to rotate or remove stimuli from the palm).

Videotape Recording and Scoring. The exploratory activity of each $S$ in haptic groups was recorded on videotape with a Sony videotape recording system. The camera, tripod-mounted and about $2.5 \mathrm{~m}$ to the left front of $\mathrm{S}$, looked downward onto the stimulus. A $90-\mathrm{mm}$ telephoto lens served to enlarge the image.

At the conclusion of the experiment, a scorer, previously trained by Es, analyzed the videotapes. The scorer's task was to categorize the scanning techniques used by a $S$ each time he felt a stimulus, noting only whether particular methods occurred. The tapes were scored for four methods-global search, detailed search, palmar search, and tracing-defined by the Es after a study of the tapes. Global search consisted of using the fingers and thumb independently to explore several aspects of the stimulus (i.e., hump, protuberances, and spaces) simultaneously. Detailed search involved the coordinated use of fingers and thumb to search a single aspect of the stimulus at a time and usually included the successive searching of several aspects. Palmar search involved pressing the palm downward on the top of the stimulus, taking an almost passive imprint of the relative locations of stimulus aspects. Finally, tracing consisted of using one or two fingers to trace the fingertips around different stimulus aspects.

Five 1-h training sessions for the scorer preceded the scoring and followed the procedures described by Davidson (1972).

\section{Results}

Matching Errors. The mean errors per group in
Table 1 were compared with an analysis of variance design which permitted a two-way factorial analysis of the four haptic groups (standard exploration time vs comparison exploration time) and also compared all haptic groups to the visual control group (Winer, 1971, p. 468). This statistic revealed significant main effects of standard exploration time, $F(1,35)=6.66, p<.05$, and comparison exploration time, $F(1,35)=5.22, p<.05$, and no significant interaction. There was also a significant difference between all TT groups and the VV group, $F(1,35)=19.24, p<.01$. Table 1 shows that increasing either standard or comparison exploration time improved accuracy, and that increasing both standard and comparison exploration time led to the most accurate matching. Indeed, Dunnett's $t$ tests indicated that the TT-16,16 group was the only one of the haptic matching groups that did not differ significantly from the VV-4,4 group, $t(35)=1.87$, $p>.05$. [The other comparisons with the VV $-4,4$ group were as follows: TT $-4,4, \mathrm{t}(35)=5.31, \mathrm{p}<.005$; TT $-4,16, \mathrm{t}(35)=2.81, \mathrm{p}<.025 ;$ TT-16,4, $\mathrm{t}(35)=2.60$, $\mathrm{p}<.025]$.

Exploratory Search. Following a check for scorer reliability, ${ }^{1}$ we calculated the percentage of each S's judgments in which the scorer observed each scanning method and obtained group averages (each time the $\mathrm{S}$ felt a stimulus was treated as a judgment, hence there were four judgments per trial). The resulting distributions, shown in Fig. 1 and compared with separate Kruskal-Wallis one-way analyses of variance for each scanning method, differed significantly in global search, $H(3)=10.18, p<.02$, and tracing, $H(3)=16.13$, $\mathrm{p}<.001$. Figure 1 shows that the principal differences are between the TT-4,4 and TT-16,16 groups involving a decreased use of global search by the latter group, coupled with increases in usage of the other methods. The remaining TT-4,16 and TT-16,4 groups appear to lie somewhere between the TT-4,4 and TT-16,16 distributions, with a reduction in global search but no pronounced increases in frequency of other methods.

Since exploration time was factored between standard and comparison phases of the task, we compared percentage usage of each scanning method during standard judgments only with usage during comparison judgments only with Mann-Whitney $U$ tests. The only differences occurred in the TT-16,4 group, where usage in standard judgments significantly exceeded comparison judgments for detailed search, $\mathrm{U}(8,8)=3.5, \mathrm{p}<.01$, palmar search, $\mathrm{U}(8,8)=15.0, \mathrm{p}<.05$, and tracing, $\mathrm{U}(8,8)=14.0, \mathrm{p}<.05$. Indeed, the distribution of search methods on standard judgments in this group looked just like the overall pattern observed for TT-16,16 Ss, whereas search on comparison judgments looked like the overall pattern for TT-4,4 Ss.

We compared the number of scanning strategies used per judgment, shown in Table 2 , in a three-way analysis of variance, revealing significant interactions between 
phase of task (i.e., standard or comparison judgments) and standard exploration time, $F(1,27)=36.44, p<.01$, phase of task and comparison exploration time, $F(1,27)$ $=9.17, \mathrm{p}<.01$, and standard and comparison exploration times, $F(1,27)=8.63, p<.01$. Table 2 indicates that (a) increasing standard exploration time leads to use of the greatest number of methods regardless of comparison exploration time, (b) increasing comparison exploration time led to increased numbers of methods on comparison judgments only when standard exploration time was also increased, and (c) increasing standard exploration time led to increased numbers of methods on standard judgments, even though comparison array time was not also increased.

\section{EXPERIMENT II}

\section{Method}

Subjects. The Ss were 73 undergraduate volunteers.

Procedure. The stimuli and task situation were the same as in Experiment I. The only difference involved the experimental groups. Thirty-seven Ss were rand omly assigned to a haptic-visual matching group (TV), exploring standards by hand and comparisons by eye, and 36 Ss assigned to a visual-haptic group (VT), exploring standards by eye and comparisons by hand. Within each group, approximately $25 \%$ of the Ss explored standards for $4 \mathrm{sec}$ and comparisons for $4 \sec$ each $(4,4)$, another $25 \%$ explored standards for $4 \mathrm{sec}$ and comparisons for $16 \mathrm{sec}$ each $(4,16)$, a third $25 \%$, standards for $16 \mathrm{sec}$ and comparisons for $4 \mathrm{sec}$ each $(16,4)$, and the last $25 \%$, standards and comparisons for $16 \mathrm{sec}$ each $(16,16)$.

Stimuli were presented in a lookie-feelie box. A lower chamber with two holes in its front was added to the stage used in Experiment $I$. The $S$ placed his hands through the holes to feel stimuli, whereas he viewed stimuli on the stage as in Experiment I.

Videotape recording and scoring procedures were as in Experiment I, except that Ss in only the TV-4,4, TV-16,4,

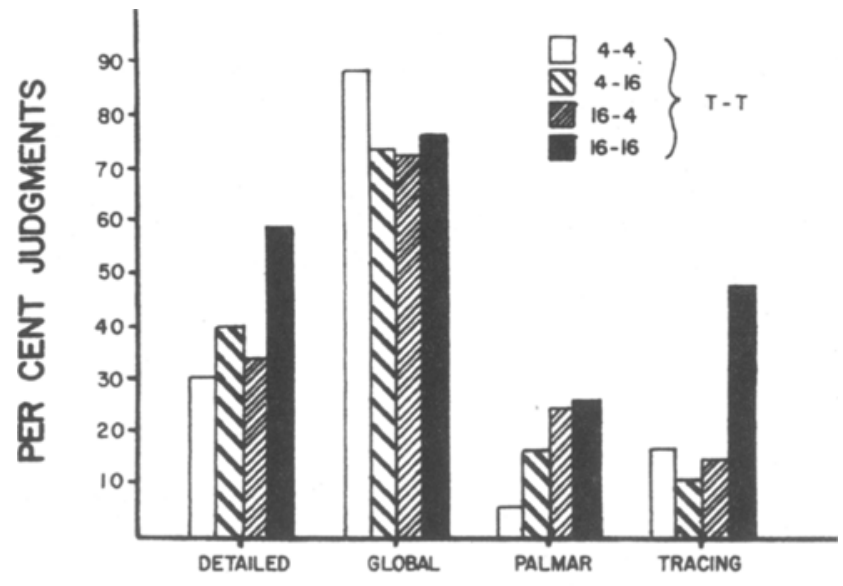

SCANNING STRATEGY

Fig. 1. The percentage of judgments in which TT Ss in Experiment I used the scanning strategies. (Each $S$ had 20 trials and made four judgments per trial. More than one strategy could occur in each judgment. KruskarWallis analyses of variance revealed significant differences among the four groups in usage of global search, $\mathrm{p}<.01$, and tracing, $\mathrm{p}<.001$.)
Table 2

Number of Scanning Strategies Used Per Judgment

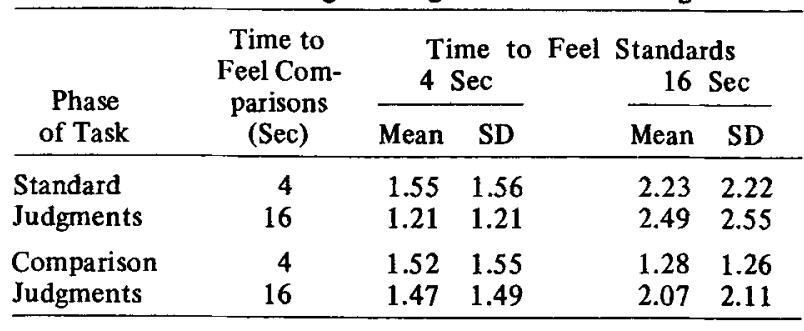

Table 3

Mean Cross-Modal Matching Errors

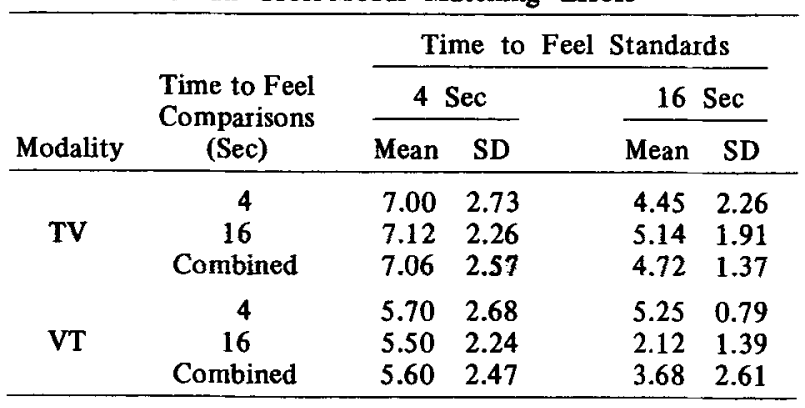

VT $-4,4$, and VT- 4,16 groups were recorded. (Only about $85 \%$ of the $\mathrm{Ss}$ in these groups were recorded due to a shortage of videotapes.)

\section{Results}

Matching Errors. The mean cross-modal matching errors are given in Table 3. A three-way factorial analysis of variance revealed main effects for both modality and standard exploration time, but no effect of comparison exploration time. We therefore pooled scores over the comparison exploration time groups and performed a two-way analysis of variance on the resulting data. Significant main effects were found for both modality, $F(1,69)=5.72, p<.01$, and standard exploration time, $F(1,69)=14.01, p<.01$. Subsequent $t$ tests revealed that with 4 sec to explore standards, TV matching was significantly less accurate than VT matching, $t(69)=$ $1.79, \mathrm{p}<.025$, but no difference existed between these two groups when standard exploration time was increased to $16 \mathrm{sec}, t(69)=1.18, \mathrm{p}>.05$. Also, increasing standard exploration time significantly improved matching in both the TV group, $t(69)=2.77$, $\mathrm{p}<.005$, and the VT group, $\mathrm{t}(69)=2.23, \mathrm{p}<.025$.

Exploratory Search. Scanning usage per group was summarized as in Experiment $I$, and the resulting distributions were compared with separate Kruskal-Wallis analyses of variance for each scanning method. There were significant differences among the distributions for detailed search, $H(3)=14.07, p<.01$, and palmar search, $H(3)=8.20, p<.05$. Figure 2 shows the scanning data, revealing (a) practically no difference between the distributions for the two VT groups, both showing a pattern similar to TT-4,4 Ss in Experiment I, and (b) a similarity in the scanning of both TV groups to 


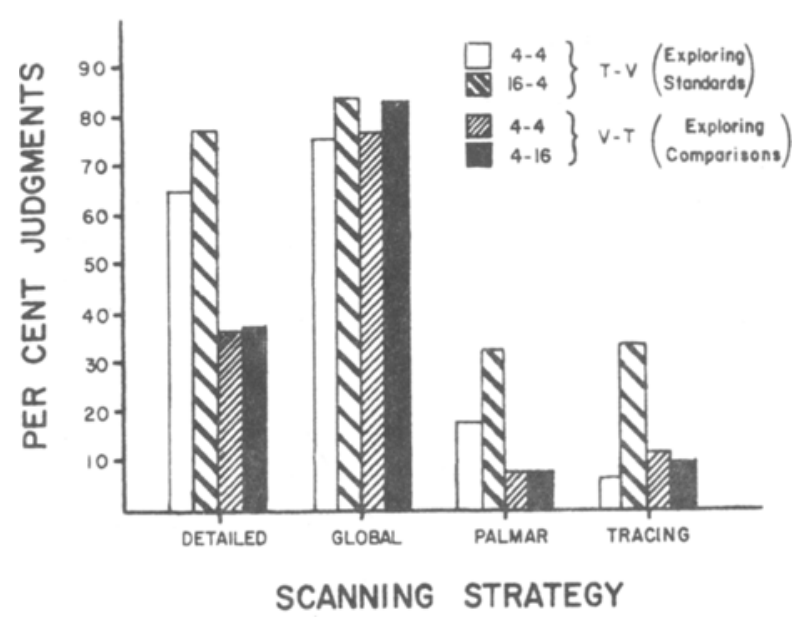

Fig. 2. The percentage of judgments in which $S$ s in Experiment II used the scanning strategies. (TV Ss made 20 hap tic judgments, and VT Ss, 60 haptic judgments. More than one strategy could occur in each judgment. Kruskal-Wallis analyses of variance revealed significant differences among the four groups in usage of detailed search, $p<.01$, and palmar search, $\mathrm{p}<$.05.)

the pattern shown by TT-16,16 Ss in Experiment I, this more the case with the TV-16,4 group than with the TV $-4,4$ Ss.

Table 4 shows the mean number of strategies used per judgment, and a one-way analysis of variance indicated that the four groups differed significantly, $F(3,26)=$ $17.94, \mathrm{p}<.01$. A subsequent Newman-Keuls test showed that the TV-16,4 group used more strategies per judgment than any other group, $p<.01$, and that the two VT groups did not differ from one another.

\section{GENERAL DISCUSSION}

The present experiments implicate haptic exploration time as an apparently important determinant of accuracy in matching within touch and across touch and vision. Goodnow's (1971) report of a large difference in errors between TT and VV groups in favor of vision was replicated in Experiment $I$ and then substantially reduced by increasing haptic search time so that touch was nearly as accurate as vision.

Also replicated here was Goodnow's finding of better matching from vision to touch than from touch to vision under conditions of restricted exploration time, an outcome also reported by others (Abravanel, 1973;

Table 4

Number of Scanning Strategies Used Per Judgment

\begin{tabular}{lrcc}
\hline & & Mean & SD \\
\hline \multirow{2}{*}{ Group TV } & 4,4 & 1.57 & 1.60 \\
& 16,4 & 2.27 & 2.28 \\
Group VT & 4,4 & 1.33 & 1.33 \\
& 4,16 & 1.39 & 1.39 \\
\hline
\end{tabular}

Lobb, 1970; Milner \& Bryant, 1968). Interestingly, the asymmetry of cross-modal accuracy we found was reduced only by increasing exploration time for standards, while increasing comparison exploration time had no effect. This finding, taken with the improvement in VT matching with increased standard exploration time, reinforces previous arguments (cf. Goodnow, 1971; Milner \& Bryant, 1968) that the standard exploration phase of the matching task is the most important phase with respect to accuracy.

Whereas this conclusion fits our data from cross-modal matching, it is at odds with the finding in Experiment $I$ that increases in exploration time in either phase of the haptic intramodal task improved performance. It is unclear why these different effects were obtained. One possibility is that the two task situations pose different requirements. In fact, Goodnow (1971) suggested that intramodal matching poses primarily time and interference demands on short-term retention. With intermodal matching, there is an added demand of transformation of original information about the standard so that it can be matched with input about comparisons coming from the other modality. It may be that in intramodal haptic matching even a brief exploration of the standard yields enough stable information to effect a match provided time is available to use the information in searching the comparison stimuli. The added memory demand in the intermodal condition, however, may prevent enough of the haptic input obtained from such a brief exposure to the standard from being transformed.

The changes in scanning style paralleling increased haptic exploration time reflected use of a greater variety of ways to gather information from the stimulus by hand. These results help to clarify how Ss made use of increased exploration time and also extend previous reports of correlations between haptic search style and accuracy (Abravanel, 1968; Davidson, 1972; Davidson \& Whitson, 1974; Goodnow, Baum, \& Davidson, 1971; Zinchenko \& Ruzskaia, 1960). In these studies, as in ours, the scanning related to accurate judgments probably provided increased information about properties that best differentiatd the stimuli.

\section{REFERENCES}

Abravanel, E. The development of intersensory patterning with regard to selected spatial dimensions. Monographs of the Society for Research in Child Development, 1968, 33 (Serial No. 118, No. 2 ).

Abravanel, E. Retention of shape information under haptic or visual acquisition. Perceptual \& Motor Skilis, 1973, 36, 683-690.

Caviness, J. Visual and tactual perception of solid shape. Unpublished doctoral dissertation, Cornell University. 1964.

Davidson, P. Haptic judgments of curvature by blind and sighted humans. Journal of Experimental Psychology, 1972, 93, 43.55.

Davidson, P., Barnes, J., \& Mullen, G. Differential effects of task memory demand on haptic matching of shape by blind and sighted humans. Neuropsychologia, in press.

Davidson, P., \& Whitson, T. Haptic equivalence matching of curvature by blind and sighted humans. Journal of Experimental Psychology, 1974, 102, 687-690. 
Gibson, J. Observations on active touch. Psychological Review, $1962,69,477-491$

Goodnow, J. Eye and hand: Differential memory and its effects on matching. Neuropsy chologia, 1971, 9, 89-95.

Goodnow, J., Baum, B., \& Davidson, P. A haptic error: Skew in a symmetrical curve. Perception \& Psychophysics, 1971, 10, 253-256.

Jackson, J. Development of visual and tactual processing of sequentially presented shapes. Developmental Psychology, $1973,8,46-50$.

Johnson, $G$. The development of visual and haptic perception of form within and between perceptual systems. Paper read at the 43rd Meeting of the Eastern Psychological Association, Boston, Mass., April 1972.

Lobb, H. Asymmetrical transfer of form discrimination across sensory modalities in human adults. Journal of Experimental Psychology, 1970, 86, 350-354.

Milner, A. \& Bryant, P. Cross-modal matching by young children. Journal of Comparative \& Physiological Psychology, 1968, 71, 453-458.

Raskin, L. \& Scoonover, D. The influence of sensory modality and exploration time on letter-learning by preschool children. Paper read at the 43rd Meeting of the Eastern Psychological Association, Boston, Mass, April 1972.

Revesz, G. Psychology and art of the blind. London: Longmans, Green, 1950.
Rose, S., Blank, M., \& Bridger, W. Intermodal and intramodal retention of visual and tactual information in young children. Developmental Psychology, 1972, 6, 482-486.

Rudel, R., \& Teuber, H.-L. Crossmodal transfer of shape discrimination by children. Neuropsy chologia, 1964, 2, 1-8.

Winer, B. Statistical principles in experimental design. (2nd ed.) New York: McGraw-Hill, 1971.

Zinchenko, $\mathrm{V}$ \& Ruzskaia, A. Comparative analysis of touch and vision: Report IV. Development of tactile orientation and haptic-visual transfer in preschool children. Doklady Akademii Pedagogicheskikh Nauk RSFSR, 1960,3, 99-102 (JPRS Doc. 10686).

\section{NOTE}

1. We assessed scorer reliability by having one of the authors (P.W.D.) score the tapes of approximately $20 \%$ of the Ss in the sample drawn randomly from the four TT groups and obtaining the percentage agreement with the scorer, found to be about $70 \%$.

(Received for publication A ugust 3, 1973; revision received December 14, 1973.) 